\title{
ARAHAN PEMENUHAN RUANG TERBUKA HIJAU KOTA BANDA ACEH
}

\author{
Fulfillment Referrals of Banda Aceh Green Open Space
}

\section{Cut Hashfi Fadhila1 ${ }^{1}$, Kukuh Murtilaksono² dan Khursatul Munibah ${ }^{3}$}

Diterima: 7 Juni 2017 Disetujui: 16 November 2018

\begin{abstract}
Abstrak: Gempa bumi di Kota Banda Aceh tanggal 26 Desember 2004 yang diikuti tsunami dan menerjang sepanjang garis pantai Samudera Hindia memakan banyak korban jiwa dan merusak infrastruktur termasuk RTH. Artikel ini menyajikan perubahan luas dari RTH Banda Aceh pra dan pasca tsunami, kebutuhan RTH berdasarkan luas wilayah dan jumlah penduduk, serta arahan pengembangannya. Metode yang digunakan adalah intepretasi dan klasifikasi citra satelit, analisis kebutuhan RTH berdasarkan luas wilayah sesuai dengan UU No. 26 tahun 2007, analisis kebutuhan RTH berdasarkan jumlah penduduk dengan standar kebutuhan RTH per kapita dalam PERMENPU No. 5/PRT/M/2008. Konsep Program Pengembangan Kota Hijau (P2KH) digunakan untuk menyusun arahan pengembangan RTH Kota Banda Aceh, dan diintegrasikan dengan rencana penggunaan lahan dalam RTRW Kota Banda Aceh. Hasil analisa menunjukkan bahwa bahkan sebelum tsunami, RTH Banda Aceh masih jauh dari memenuhi standar UU Penataan Ruang (13,92\% dari luas wilayah). Akibat tsunami RTH Banda Aceh hanya tersisa sekitar 9,31\% dari luas wilayah. Pada tahun 2010 RTH Banda Aceh mengalami peningkatan menjadi 12,83\% dari luas wilayah, dan pada tahun 2015 Banda Aceh memiliki RTH sekitar 37,51\% dari luas wilayah kota. Kebutuhan RTH Banda Aceh berdasarkan luas wilayah adalah 1.227,18 ha publik dan 613,59 ha privat, berdasarkan prediksi jumlah penduduk tahun 2029 adalah 687,89 ha. Arahan pengembangan RTH Banda Aceh adalah intensifikasi dengan peningkatan kualitas RTH yang tersedia dan ekstensifikasi dengan mengakuisisi lahan privat untuk RTH.
\end{abstract}

\section{Kata kunci: Akuisisi, Banda Aceh, Ruang Terbuka Hijau Publik, Tsunami}

\begin{abstract}
The earthquake that occurred in Banda Aceh on December 262004 followed by tsunami along the coastline of the Indian Ocean caused a huge number of casualties and infrastructure destruction including green open space. This article presents the change of Banda Aceh green open space before and after tsunami, the requirement of Banda Aceh green open space based on vast territory and population, and the development direction of Banda Aceh green open space. The applied method was image interpretation and classification, analysis of green open space requirement was calculated based on vast territory in accordance with Act No. 26/2007, based on population with green open space requirement standard per capita as in PERMENPU No. 5/PRT/M/2008. Green City Development Program (P2KH) concept which was applied to arrange the development direction of Banda Aceh green open space, and integrated with the land use plan in RTRW of Banda Aceh. The result of green open space wide before and after tsunami analysis showed that even before tsunami, Banda Aceh green open space still far from sufficient as required of spatial planning constitution (13,92\% of the city area). Right after tsunami, Banda Aceh green
\end{abstract}

\footnotetext{
${ }^{1}$ Program Studi Ilmu Perencanaan Wilayah, Sekolah Pascasarjana, IPB

${ }^{2}$ Departemen Ilmu Tanah dan Sumberdaya Lahan, Fakultas Pertanian, IPB

${ }^{3}$ Departemen Ilmu Tanah dan Sumberdaya Lahan, Fakultas Pertanian, IPB
} 
open space was reduced to only remaining about 9,31\% of the city area. Five years later (2010) Banda Aceh green open space was increased to $12,83 \%$ of the city area, and by the year of 2015 Banda Aceh has green open space about 37,51\% of the city area. The requirement of Banda Aceh green open space based on vast territory is $1.227,18$ ha public green open space and 613,59 ha private green open space, based on total population predicted by 2029 is 687,89 ha. The development direction of Banda Aceh green open space is intensification by increasing the quality of existing green open space and extensification by acquisition of private land for green open space.

Keywords: Acquisition, Banda Aceh, Public Green Open Space, Tsunami

\section{PENDAHULUAN}

Ruang Terbuka Hijau (RTH) memiliki peran yang penting bagi kehidupan manusia dan pembangunan kota berkelanjutan serta mampu memberi manfaat ekonomi, sosial dan lingkungan (Chiesura, 2004; Zhou \& Wang, 2011; Yuhong et al. 2014). Undang-Undang Nomor 26 Tahun 2007 tentang Penataan Ruang pasal 29 yang menyebutkan bahwa proporsi RTH pada wilayah kota minimal 30\% dari luas wilayah kota (RTH publik minimal sebesar $20 \%$ dan RTH privat 10\% dari luas wilayah kota). Dalam Peraturan Menteri PU No. 5 tahun 2008 tentang Pedoman Penyediaan dan Pemanfaatan RTH di Kawasan Perkotaan dijelaskan bahwa luas RTH kota minimum tersebut merupakan ukuran minimum untuk menjamin keseimbangan ekosistem kota, baik keseimbangan sistem hidrologi dan keseimbangan mikrolat, maupun sistem ekologis lain yang dapat meningkatkan ketersediaan udara bersih, serta dapat meningkatkan nilai estetika kota

Tragedi gempa bumi yang berpusat di Samudra Hindia pada tanggal 26 Desember 2004 merupakan gempa terbesar dalam kurun waktu 40 tahun terakhir. Ketinggian gelombang muka air laut saat tsunami mencapai daratan (run up height) terukur setinggi 20 meter, genangan (inundation) bisa menghempas daratan sejauh 8 kilometer jauhnya dari pinggir pantai (Zaiyana dan Buchori 2014). Gempa bumi tersebut diikuti oleh tsunami yang menghantam Aceh, Sumatera Utara, Malaysia, Thailand, Pantai Timur India, Sri Lanka, bahkan sampai Pantai Timur Afrika. Di Kota Banda Aceh lebih dari separuh infrastruktur rusak akibat terkena gelombang tsunami termasuk ruang terbuka hijau kota.

Sebelum bencana tsunami pada tahun 2004 Kota Banda Aceh melalui Qanun Nomor 3 Tahun 2003 tentang Rencana Tata Ruang Wilayah Kota Banda Aceh Tahun 2002-2010 telah mencantumkan pengaturan RTH Kota Banda Aceh termasuk kawasan-kawasan yang ditetapkan sebagai RTH. Sebelum rencana tersebut direalisasikan sepenuhnya, Kota Banda Aceh dilanda bencana sehingga diperkirakan RTH kota pada saat itu masih belum memenuhi standar minimal $30 \%$ dari luas wilayah kota. Pada tahun 2009 Pemko Banda Aceh mensahkan Qanun Nomor 4 tahun 2009 tentang Rencana Tata Ruang Wilayah Kota Banda Aceh Tahun 2009-2029 yang turut mengatur tentang ruang terbuka hijau Kota Banda Aceh menggantikan qanun sebelumnya. Satu tahun setelah qanun tersebut ditetapkan, pembangunan RTH kota masih belum optimal dikarenakan fokus pembangunan sebelumnya lebih dititik beratkan pada upaya rekonstruksi sarana prasarana yang rusak karena tsunami.

Kota Banda Aceh hingga tahun 2015 atau 6 tahun setelah ditetapkannya Qanun Nomor 4 tahun 2009 baru mampu menyediakan 13,2\% RTH dari target sebesar 20\% RTH publiknya. Permasalahan yang umum dijumpai adalah pembangunan bangunan fisik lain di juga terus meningkat seiring bertambahnya jumlah penduduk dan kebutuhan masyarakat akan sarana dan prasarana kota. Menjamurnya bangunan-bangunan pertokoan, gedung dan fasilitasi lain sebagai prasana masyarakat dalam aktifitasnya adalah hal yang tidak dapat dihindari pada sebuah kota yang sedang berkembang. Mengingat hingga saat ini luas RTH publik Kota Banda Aceh kurang dari 20\%, maka pengembangan harus disiapkan sejak dini dengan terus berupaya menambah luas RTH publik yang menjadi tanggung jawab Pemerintah Kota Banda Aceh dikarenakan Kota Banda Aceh terus mengalami percepatan 
pembangunan fisik sehingga dikhawatirkan akan semakin mempersulit pengembangan RTH dimasa mendatang.

Program Pengembangan Kota Hijau (P2KH) yang dicetuskan oleh pemerintah pusat pada tahun 2011 melalui Kementerian Pekerjaan Umum secara bertahap terus dilaksanakan oleh Pemkot Banda Aceh diantaranya dengan meningkatkan kualitas dan kuantitas RTH sebagai salah satu dari 8 atribut Kota Hijau. Konsep pengembangan RTH sendiri didasarkan dari Panduan P2KH, Peraturan Menteri Pekerjaan Umum Nomor: 05/PRT/M/2008 tentang Pedoman Penyediaan dan Pemanfaatan Ruang Terbuka Hijau di Kawasan Perkotaan, dan standar kebutuhan $20 \%$ RTH publik dan $10 \%$ RTH privat seperti yang diamanatkan oleh Undang-Undang Nomor 26 Tahun 2007 tentang Penataan Ruang. Penelitian ini bertujuan untuk: 1). Menganalisis perubahan luas RTH Kota Banda Aceh pra dan pasca tsunami; 2). Menghitung kebutuhan luas RTH Kota Banda Aceh berdasarkan luas wilayah dan jumlah penduduk; 3). Menyusun arahan pengembangan RTH publik Kota Banda Aceh.

\section{METODE}

\section{Lokasi}

Penelitian dilaksanakan di Kota Banda Aceh - Provinsi Aceh yang secara geografis terletak pada $05^{\circ} 16^{\prime} 15^{\prime \prime}-05^{\circ} 36^{\prime} 16^{\prime \prime}$ Lintang Utara dan $95^{\circ} 16^{\prime} 15-95^{\circ} 22^{\prime} 35^{\prime \prime}$ Bujur Timur dengan tinggi rata-rata 0,80 meter di atas permukaan laut. Kota Banda Aceh mempunyai luas wilayah $61,36 \mathrm{~km}^{2}$ yang terbagi atas 9 kecamatan, 17 kemukiman, dan 90 gampong (BPS 2016). Kegiatan penelitian ini dilaksanakan selama empat bulan yaitu pada bulan Juli sampai dengan Oktober 2016.

\section{Jenis dan Sumber Data}

Data yang digunakan dalam penelitian berupa data primer dan data sekunder. Data primer diperoleh dari survei lapang untuk mengamati jenis dan klasifikasi RTH yang terdapat di Kota Banda Aceh. Data sekunder terdiri dari Dokumen dan Peta RTRW Kota Banda Aceh tahun 2009-2029, Peta Administrasi Kota Banda Aceh, Banda Aceh Dalam Angka 2016, Peta Penggunaan Lahan Kota Banda Aceh tahun 2004 dan 2010, Tsunami Damage Asessment Map, dan Citra SPOT 6 Kota Banda Aceh tahun 2015.

\section{Metode Analisis Data}

\section{Analisis Perubahan Ruang Terbuka Hijau}

Gambaran perubahan RTH diawali dengan melakukan overlay dengan peta batas administrasi wilayah Kota Banda Aceh. Penggunaan lahan Kota Banda Aceh tahun 2015 diperoleh dari digitasi on screen citra SPOT 6 tahun 2015 dengan melakukan interpretasi visual didukung survei lapang. Proses selanjutnya yang dilakukan adalah menumpangtindihkan peta penggunaan lahan 2004, tsunami damage assessment map, peta penggunaan lahan 2010, peta penggunaan lahan 2015, dengan peta administrasi. Berdasarkan proses tersebut kemudian didapatkan luas dan sebaran RTH pra dan pasca tsunami Kota Banda Aceh yang selanjutnya dianalisa secara deskriptif.

\section{Analisis Kebutuhan Ruang Terbuka Hijau}

a. Kebutuhan RTH Berdasarkan Luas Wilayah

Berdasarkan Undang Undang nomor 26 tahun 2007 tentang Penataan Ruang, menyebutkan minimal 30\% luas kota adalah RTH dengan proporsi $20 \%$ RTH publik dan $10 \%$ RTH privat. Luasan ini dimaksudkan agar tercipta suatu keseimbangan lingkungan 
perkotaan. Dengan tersedianya RTH yang memadai di lingkungan perkotaan akan tercipta lingkungan alami yang nyaman, aman dan berkelanjutan, sehingga menjadi indikasi terwujudnya keseimbangan bagi kehidupan masyarakat kotanya. Kebutuhan RTH berdasarkan luas wilayah menurut UU No. 26/2007 dapat dihitung dengan menggunakan persamaan sebagai berikut:

1. Luas RTH publik = LuasWilayah $\times 20 \%$

2. Luas RTH privat $=$ LuasWilayah $\times 10 \%$

b. Kebutuhan RTH Berdasarkan Jumlah Penduduk

Untuk menentukan luas RTH berdasarkan jumlah penduduk menurut Peraturan Menteri PU Nomor 05/PRT/M/2008 tentang Pedoman Penyediaan dan Pemanfaatan RTH di Kawasan Perkotaan dilakukan dengan mengalikan antara jumlah penduduk yang dilayani dengan standar luas RTH per kapita. Standar luas RTH Kota Banda Aceh adalah $20 \mathrm{~m}^{2} /$ kapita.

$$
\text { Luas RTH = Jumlah Penduduk x Standar Luas RTH per Kapita }
$$

Untuk menghitung proyeksi jumlah penduduk pada tahun akhir perencanaan (2029) digunakan rumus bunga berganda:

Dimana:

$$
P_{t+x}=P_{t}(1+r)^{x}
$$

$P_{t+x}$ Jumlah penduduk pada tahun $\mathrm{t}+\mathrm{x}$

$P_{t} \quad$ Jumlah penduduk pada tahun $\mathrm{t}$

$r \quad$ Rata-rata persentase pertambahan jumlah penduduk

$\mathrm{x} \quad$ Selisih tahun

\section{Penyusunan Arahan Pengembangan Ruang Terbuka Hijau}

Pengembangan RTH menekankan pada pemenuhan luasan minimal sebesar 30\% dari luas wilayah Kota Banda Aceh. RTH sebagai bagian dari ruang kota direncanakan agar dapat menjadi ruang yang saling terintegrasi untuk menciptakan kontinuitas ruang, mulai dari tingkat gampong (desa) hingga kota. Penyusunan arahan pengembangan RTH dilakukan dengan cara analisis terhadap kondisi RTH saat ini, kebutuhan RTH, dan area yang berpotensi dapat dikembangkan menjadi RTH dengan berpedoman pada RTRW Kota Banda Aceh serta Panduan Pengembangan Kota Hijau (P2KH). Hasil arahan dan strategi pengembangan RTH disajikan dalam bentuk uraian dan dipetakan secara spasial. Arahan pengembangan RTH berdasarkan Panduan Pengembangan Kota Hijau (P2KH) meliputi:

a. Menambah RTH baru;

b. Meningkatkan koridor hijau;

Penanaman pohon pada daerah koridor hijau, seperti jalur hijau dan jalan tol, jalur pedestrian, sempadan sungai, tepi badan air/waduk, sempadan rel kereta api, saluran listrik tegangan tinggi, bakau di sepanjang pantai.

c. Mengakuisisi RTH Privat menjadi bagian RTH publik;

1) Penerapan koefisien dasar hijau (KDH) pada lahan-lahan privat yang dimiliki masyarakat dan swasta diterapkan pada pengurusan izin mendirikan bangunan;

2) Pemda dapat mulai mendata dan menetapkan RTH privat pekarangan rumah, sekolah, perkantoran, hingga pengembangan (kawasan terpadu, pusat perbelanjaan, hotel, apartemen) sebagai bagian dari RTH kota;

3) Kepada para pengembang, diminta untuk memenuhi kewajiban penyediaan fasilitas sosial dan fasilitas umum. Dalam pengembangan kawasan dikenakan prasyarat KDH minimal 20 persen berupa taman di kawasan pengembang; 
4) Warga diajak berperan serta mengelola lahan hijau pekarangan melalui penanaman pohon rindang dan karpet hijau tanaman dan pembuatan lubang biopori;

5) Pemberian insentif bagi warga mengizinkan lahannya untuk diakuisisi berupa keringanan pajak, pajak air tanah, pembayaran tagihan listrik dan telepon.

d. Peningkatan kualitas RTH kota melalui refungsionalisasi RTH, contohnya:

1) Revitalisasi kawasan hutan bakau;

2) Revitalisasi situ, danau, waduk, sebagai daerah resapan air;

3) Penanaman rumput pada taman-taman lingkungan permukiman yang diperkeras (lapangan bulu tangkis, tenis, dan lain-lain).

\section{HASIL DAN PEMBAHASAN}

\section{Perubahan RTH Kota Banda Aceh Pra dan Pasca Tsunami}

Perubahan RTH Kota Banda Aceh prad an pasca tsunami dapat dilihat pada Tabel 1. Pada tahun 2004 luas RTH Kota Banda Aceh secara keseluruhan yaitu 853,87 ha atau sekitar $13,92 \%$ dari luas wilayah kota. Pasca tsunami luas RTH mengalami penurunan sebesar 282,91 ha atau sekitar $33,13 \%$. Pasca bencana tsunami RTH yang tersisa hanya seluas 570,09 ha atau 9,31\% dari luas wilayah kota. Bencana tsunami yang terjadi berdampak terhadap lebih dari separuh wilayah Kota Banda Aceh. Dampak paling parah terjadi di wilayah pesisir, menghancurkan seluruh hutan bakau dan hampir setengah dari RTH yang ada, "memusnahkan" dua kecamatan serta menelan korban jiwa yang tidak sedikit. Wilayah yang mengalami kerusakan terparah adalah yang berada di wilayah pesisir meliputi kecamatan Meuraxa, kecamatan Jaya Baru dan Kuta Raja.

Menurut Tanioka dan rekan-rekan (2006), gempa dahsyat yang terjadi di Aceh tanggal 26 Desember 2004 mengakibatkan perpindahan yang diperkirakan mencapai $23 \mathrm{~m}$ di batas lempeng didasar laut sebelah barat di lepas pantai Aceh, $21 \mathrm{~m}$ di batas lempeng di bawah Pulau Simeulue bagian utara, gelinciran (slip) sebesar 10-15 m terdapat di batas lempeng dekat Little Andaman and Car Nicobar Inlands. Menurut survei BPN Aceh di tahun 2005, terdapat dua kecamatan yang dapat dikatakan 'musnah' akibat tsunami, yaitu Kecamatan Meuraxa dan Kecamatan Kutaraja.

Tabel 1. Perubahan Luas RTH Kota Banda Aceh Prad an Pasca Tsunami

\begin{tabular}{|c|c|c|c|c|c|c|c|c|c|}
\hline \multirow{2}{*}{ No. } & \multirow{2}{*}{ Jenis RTH } & \multicolumn{8}{|c|}{ Tahun } \\
\hline & & 2004 & $\%$ & $2004^{*}$ & $\%$ & 2010 & $\%$ & 2015 & $\%$ \\
\hline 1 & Taman Kota & 6,19 & 0,10 & 1,54 & 0,03 & 12,36 & 0,20 & 52,71 & 0,86 \\
\hline 2 & Hutan Kota & 94,26 & 1,54 & 87,94 & 1,43 & 9,19 & 0,15 & 25,36 & 0,41 \\
\hline 3 & Jalur Hijau Jalan & 21,78 & 0,35 & 17,32 & 0,28 & 38,09 & 0,62 & 40,92 & 0,67 \\
\hline 4 & Sempadan Sungai & 37,77 & 0,62 & 23,48 & 0,38 & 78,60 & 1,28 & 129,54 & 2,11 \\
\hline 5 & Pemakaman & 7,38 & 0,12 & 8,23 & 0,13 & 9,67 & 0,16 & 20,87 & 0,34 \\
\hline 6 & Lapangan Olahraga & 10,48 & 0,17 & 7,53 & 0,12 & 28,01 & 0,46 & 57,23 & 0,93 \\
\hline 7 & Hutan Bakau & 0,08 & 0,00 & 0,00 & 0,00 & 50,99 & 0,83 & 483,90 & $7 ., 89$ \\
\hline 8 & Pertanian Kota & 534,70 & 8,71 & 390,36 & 6,36 & 333,11 & 5,43 & 831,50 & 13,55 \\
\hline 9 & Semak Belukar & 104,12 & 1,70 & 24,11 & 0,39 & 183,48 & 2,99 & 457,13 & 7,45 \\
\hline 10 & Padang Rumput & 37,10 & 0,60 & 10,45 & 0,17 & 43,60 & 0,71 & 202,31 & 3,30 \\
\hline & Total (ha) & 853,87 & 13,92 & 570,96 & 9,31 & 787,09 & 12,83 & 2301,46 & 37,51 \\
\hline
\end{tabular}

Keterangan: *Tanggal 29 Desember 2004

Sumber: Dinas LHK2, BAPPEDA Kota Banda Aceh dan Hasil Pengolahan Data

Tahun 2010 pembangunan infrastrutur kota yang sebelumnya hancur masih terus dilaksanakan tidak terkecuali pembangunan RTH. Luas RTH Kota Banda Aceh tahun 2010 seluas 787,09 ha atau sekitar 12,83 \% dari total luas wilayah kota. Angka ini masih lebih kecil 
bila dibandingkan dengan luas RTH tahun 2004 sebelum bencana tsunami melanda. Akibat bencana gempa dan tsunami ini, Kota Banda Aceh mengalami perubahan penggunaan lahan, migrasi penduduk dari kawasan pesisir dan diikuti pula dengan terjadinya perubahan struktur pusat-pusat pelayanan yang bergeser semakin menjauh dari pantai. Dampaknya adalah terjadi pergeseran aktivitas pembangunan kota yang mengarah ke wilayah selatan yang merupakan wilayah pinggiran kota atau sub urban.

Intensitas kegiatan pembangunan yang tinggi kearah selatan kota terutama di wilayah yang tidak terdampak tsunami seperti Kecamatan Lueng Bata. Terjadi peningkatan yang sangat signifikan bagi kawasan permukiman, dimana perubahan ini lebih mengarah kepada kegiatan rumah toko, rumah sewa, rumah kantor, dan jasa komersial lainnya. Bangunanbangunan tersebut didirikan di antara kelompok bangunan yang sudah ada sebelumnya atau pada kawasan baru salah satunya dengan mengubah RTH khususnya lahan pertanian menjadi permukiman. Hal ini berbanding terbalik dengan Kecamatan Meuraxa yang mengalami kerusakan parah. Pasca tsunami wilayah terbangun di kecamatan ini justru mengalami penurunan bila dibandingkan sebelum tsunami. Kawasan yang tadinya merupakan permukiman ditinggalkan oleh masyarakat yang trauma akan tsunami dan dibiarkan menjadi lahan-lahan terbuka yang tidak berpenghuni.

Untuk mengendalikan daerah rawan bencana Pemerintah Kota Banda Aceh membuat kebijakan yaitu dengan menurunkan tingkat pelayanan di wilayah pesisir hingga $3 \mathrm{~km}$ dari garis pantai. Sebelum tsunami kawasan ini merupakan sub pusat pelayanan pemerintahan kota Banda Aceh yang berpusat di daerah Ulee Lheue di Kecamatan Meuraxa yang merupakan kawasan pelabuhan, wisata dan pemukiman, pasca tsunami kawasan ini diturunkan menjadi kawasan biasa tidak direkomendasikan lagi untuk kegiatan palayanan. Meskipun Desa Ulee Lheue dan sekitarnya merupakan kawasan rawan bencana namun masyarakat disana masih tetap bermukim di daerah ini sehingga pemerintah menyediakan jalur-jalur evakuasi dan escape building jika terjadi bencana tsunami.

Pada tahun 2011 Pemerintah Pusat melalui Kementerian Pekerjaan Umum mencetuskan Program Pengembangan Kota Hijau (P2KH) yang diawali dengan melibatkan $60 \mathrm{Kota} / \mathrm{Kabupaten}$ diseluruh Indonesia sebagai peserta dalam pelaksanaan Program P2KH dan Kota Banda Aceh sebagai salah satu Kota yang terlibat sejak tahun 2011 hingga tahun 2015. Sejalan dengan pengembangan kota hijau yang diupayakan oleh pemerintah Kota Banda Aceh dengan visi menjadikan Kota Banda Aceh sebagai kota terhijau di Indonesia tahun 2034 dimana salah satu kebijakannya adalah penyediaan RTH publik sebesar 20,52\% pada tahun 2029 seperti yang termuat dalam RTRW Kota Banda Aceh Tahun 2009-2029 yang disahkan melalui Qanun Nomor 4 Tahun 2009.

Atas dasar regulasi tersebut, Pemerintah Kota Banda Aceh mulai mengembangkan secara bertahap pembangunan berbasiskan green city dengan cara menata Taman Taman Kota, Hutan Kota, Jalur Hijau Jalan, Penataan Jalur Hijau Sungai, menata jalur sepeda, serta meningkatkan kuantitas RTH Perkotaan dengan melakukan pembebasan lahan kawasan permukiman yang akan difungsikan sebagai Taman Kota dan Hutan Kota. Maka tidaklah mengherankan jika dibandingkan dengan tahun 2010, Banda Aceh saat ini lebih hijau dibanding tahun-tahun sebelumnya, bahkan dibanding sebelum bencana tsunami melanda. Luas RTH Kota Banda Aceh tahun 2015 adalah 2.301,47 ha atau sekitar 37,51 \% dari total luas wilayah kota. Penyumbang RTH terbesar berasal dari RTH privat yaitu 24,30 \% dari wilayah Kota Banda Aceh, lebih besar dibanding standar minimal $10 \%$ yang ditetapkan.

\section{Identifikasi RTH Kota Banda Aceh}

Berdasarkan hasil analisa citra SPOT 6 Kota Banda Aceh tahun 2015, cek lapang, dan data inventarisasi RTH publik Kota Banda Aceh tahun 2016 Dinas Kebersihan dan Keindahan seperti yang terlihat pada Gambar 1, luas RTH adalah 2.301,47 ha atau sekitar 
$37,51 \%$ dari total luas wilayah kota. Penyumbang RTH terbesar berasal dari RTH privat yaitu $24,30 \%$ dari wilayah Kota Banda Aceh atau seluas 1.490,93 ha berupa lahan pertanian perkotaan dan pekarangan, lebih besar dibanding standar minimal $10 \%$ yang ditetapkan. RTH publik sendiri hanya menempati $13,21 \%$ dari luas wilayah kota atau seluas 810,52 ha berupa taman kota, hutan kota, jalur hijau, lapangan olahraga, pemakaman, dan hutan bakau (Tabel 2 ).

Tabel 2. Inventarisasi RTH Kota Banda Aceh Tahun 2015

\begin{tabular}{|c|c|c|c|c|c|c|c|c|c|c|c|}
\hline \multirow{2}{*}{ Jenis RTH } & \multicolumn{9}{|c|}{ Kecamatan } & \multirow[t]{2}{*}{$\begin{array}{c}\text { Jumlah } \\
\text { (ha) }\end{array}$} & \multirow[t]{2}{*}{$\%$} \\
\hline & $\begin{array}{l}\text { Meur } \\
\text { axa }\end{array}$ & $\begin{array}{l}\text { Jaya } \\
\text { Baru }\end{array}$ & $\begin{array}{c}\text { Banda } \\
\text { Raya }\end{array}$ & $\begin{array}{c}\text { Baitu } \\
\text { rrah } \\
\text { man }\end{array}$ & $\begin{array}{c}\text { Luen } \\
\text { g } \\
\text { Bata }\end{array}$ & $\begin{array}{c}\text { Kuta } \\
\text { Ala } \\
\text { m }\end{array}$ & $\begin{array}{l}\text { Kuta } \\
\text { Raja }\end{array}$ & $\begin{array}{l}\text { Syiah } \\
\text { Kuala }\end{array}$ & $\begin{array}{c}\text { Ulee } \\
\text { Kare } \\
\text { ng }\end{array}$ & & \\
\hline Publik & $\begin{array}{r}187,6 \\
1 \\
\end{array}$ & 23,15 & 38,17 & $\begin{array}{r}44,6 \\
0 \\
\end{array}$ & $\begin{array}{r}23,2 \\
5 \\
\end{array}$ & $\begin{array}{r}109 \\
38 \\
\end{array}$ & $\begin{array}{r}140, \\
59 \\
\end{array}$ & $\begin{array}{r}218,2 \\
4 \\
\end{array}$ & 25,54 & 810,52 & $\begin{array}{r}13,2 \\
1 \\
\end{array}$ \\
\hline Taman Kota & 11,18 & 5,25 & 0,47 & $\begin{array}{r}20,5 \\
6\end{array}$ & 4,28 & 4,64 & 0,00 & 4,33 & 2,01 & 52,71 & 0,86 \\
\hline Hutan Kota & 0,00 & 0,00 & 0,10 & 7,37 & 0,00 & 2,71 & 2,30 & 12,88 & 0,00 & 25,36 & 0,41 \\
\hline Jalur Hijau Jalan & 5,04 & 1,58 & 1,12 & 3,94 & 7,98 & 5,68 & 0,10 & 10,91 & 4,58 & 40,92 & 0,67 \\
\hline $\begin{array}{l}\text { Sempadan } \\
\text { Sungai }\end{array}$ & 6,69 & 2,24 & 19,77 & 6,21 & 9,46 & 5,71 & $\begin{array}{r}16,8 \\
3\end{array}$ & 48,02 & 14,61 & 129,54 & 2,11 \\
\hline Pemakaman & 3,28 & 1,23 & 1,30 & 4,40 & 0,49 & 2,01 & 1,89 & 3,55 & 2,73 & 20,87 & 0,34 \\
\hline $\begin{array}{l}\text { Lapangan } \\
\text { Olahraga }\end{array}$ & 0,00 & 2,19 & 15,40 & 2,12 & 1,05 & 3,37 & 0,59 & 30,89 & 1,61 & 57,23 & 0,93 \\
\hline Hutan Bakau & $\begin{array}{r}161,4 \\
3 \\
\end{array}$ & 10,66 & 0,00 & 0,00 & 0,00 & $\begin{array}{r}85,2 \\
6 \\
\end{array}$ & $\begin{array}{r}118 \\
88 \\
\end{array}$ & $\begin{array}{r}107,6 \\
7 \\
\end{array}$ & 0,00 & 483,90 & 7,89 \\
\hline & 119,3 & 230,8 & 20994 & 84,5 & 181 & 51,0 & 43,2 & 264,7 & 306,1 & 1490,9 & 24,3 \\
\hline Privat & 6 & 6 & 209,94 & 9 & 04 & 4 & 3 & 2 & 5 & 3 & 0 \\
\hline Pertanian Kota & 74,87 & $\begin{array}{r}114,0 \\
0\end{array}$ & 132,31 & $\begin{array}{r}25,8 \\
8\end{array}$ & $\begin{array}{r}94,0 \\
2\end{array}$ & $\begin{array}{r}39,0 \\
0\end{array}$ & $\begin{array}{r}12,5 \\
8\end{array}$ & $\begin{array}{r}156,4 \\
1\end{array}$ & 182,43 & 831,50 & $\begin{array}{r}13,5 \\
5\end{array}$ \\
\hline Semak Belukar & 35,06 & 68,49 & 53,02 & $\begin{array}{r}51,0 \\
8\end{array}$ & $\begin{array}{r}54,3 \\
5\end{array}$ & 4,21 & $\begin{array}{r}26,7 \\
7\end{array}$ & 79,37 & 84,78 & 457,13 & 7,45 \\
\hline Padang Rumput & 9,43 & 48,37 & 24,61 & 7,63 & $\begin{array}{r}32,6 \\
7 \\
\end{array}$ & 7,80 & 3,88 & 28,94 & 38,98 & 202,31 & 3,30 \\
\hline Total (ha) & $\begin{array}{r}306,9 \\
7\end{array}$ & $\begin{array}{r}254,0 \\
1\end{array}$ & $\begin{array}{r}248,1 \\
1\end{array}$ & 129,19 & $\begin{array}{r}204,2 \\
9\end{array}$ & $\begin{array}{r}160,4 \\
2\end{array}$ & $\begin{array}{r}183,8 \\
2\end{array}$ & 482,96 & 331,69 & 2301,45 & $\begin{array}{r}37,5 \\
1\end{array}$ \\
\hline Persentase (\%) & 5,00 & 4,14 & 4,04 & 2,11 & 3,33 & 2,61 & 3,00 & 7,87 & 5,41 & 37,51 & \\
\hline
\end{tabular}

Sumber: Dinas LHK2 Kota Banda Aceh dan Hasil Pengolahan Data 


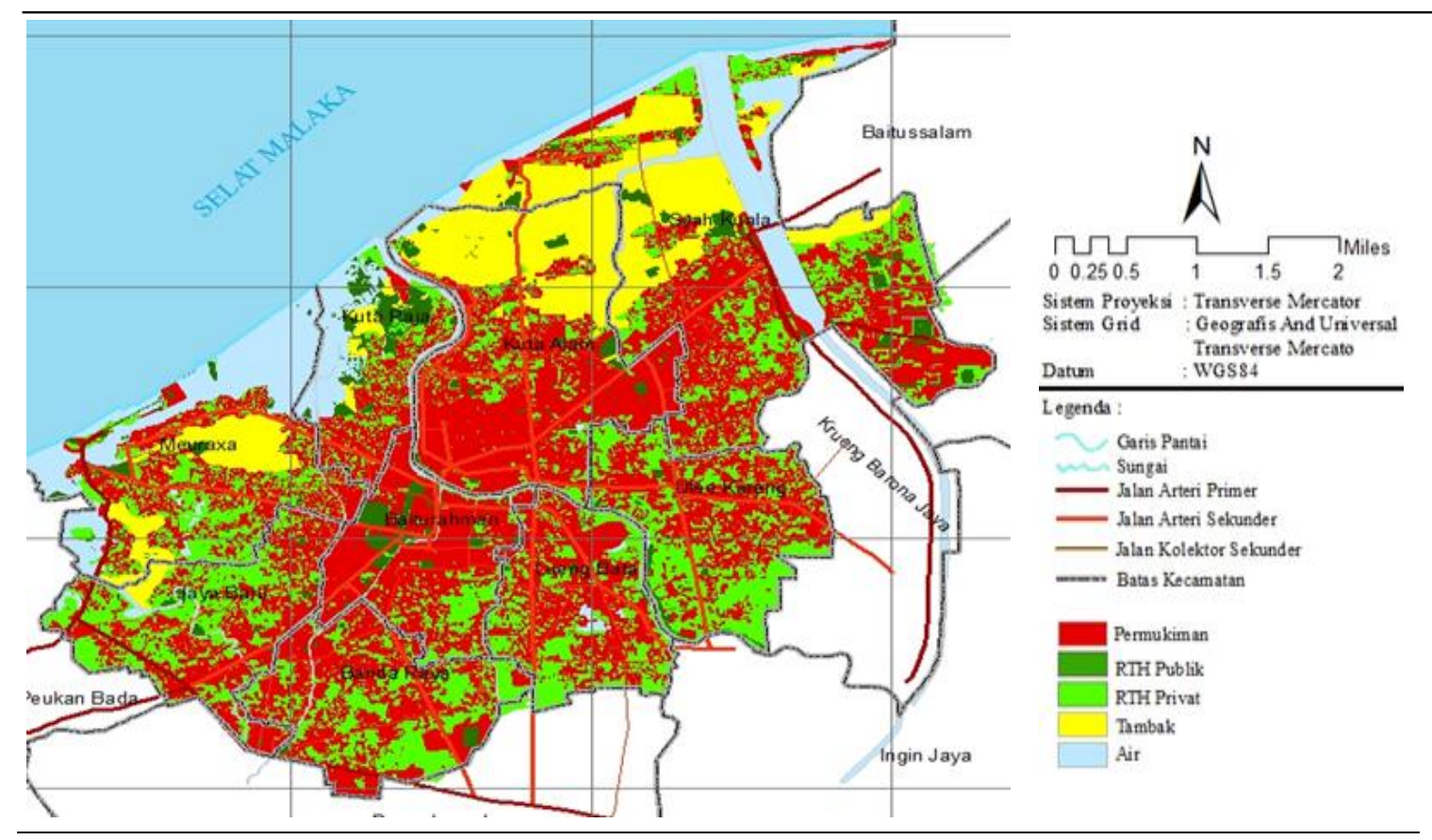

Gambar 1. Peta Penyebaran RTH Kota Banda Aceh Tahun 2015

\section{Kebutuhan RTH Berdasarkan Luas Wilayah}

Undang-Undang Nomor 26 Tahun 2007 secara khusus mengamanatkan perlunya penyediaan dan pemanfaatan ruang terbuka hijau yang proporsi luasannya ditetapkan paling sedikit 30\% dari luas wilayah kota terdiri dari 20\% RTH Publik dan 10\% RTH Privat. Kebutuhan dan kecukupan luas RTH Kota Banda Aceh dapat dilihat pada Tabel 3.

Tabel 3. Kebutuhan dan Kecukupan RTH Kota Banda Aceh Berdasarkan Luas Wilayah

\begin{tabular}{|c|c|c|c|c|c|c|c|c|}
\hline \multirow{2}{*}{ No. } & \multirow{2}{*}{ Kecamatan } & \multirow{2}{*}{ Luas Wilayah (ha) } & \multicolumn{2}{|c|}{ Kebutuhan (ha) } & \multicolumn{2}{|c|}{ Tersedia (ha) } & \multicolumn{2}{|c|}{ Kecukupan (ha) } \\
\hline & & & Publik & Privat & Publik & Privat & Publik & Privat \\
\hline 1. & Meuraxa & 725,80 & 145,16 & 72,58 & 187,61 & 119,36 & $+42,45$ & $+46,78$ \\
\hline 2. & Jaya Baru & 378,00 & 75,60 & 37,80 & 23,15 & 230,86 & $-52,45$ & $+193,06$ \\
\hline 3. & Banda Raya & 478,90 & 95,78 & 47,89 & 38,17 & 209,94 & -57.61 & $+162,05$ \\
\hline 4. & Baiturrahman & 453,90 & 90,78 & 45,39 & 44,60 & 84,59 & -46.18 & $+39,2$ \\
\hline 5. & Lueng Bata & 534,10 & 106,82 & 53,41 & 23,25 & 181,04 & -83.57 & $+127,63$ \\
\hline 6. & Kuta Alam & $1.004,70$ & 200,94 & 100,47 & 109,38 & 51,04 & -91.56 & $-49,43$ \\
\hline 7. & Kuta Raja & 521,10 & 104,22 & 52,11 & 140,59 & 43,23 & +36.37 & $-8,88$ \\
\hline 8. & Syiah Kuala & $1.424,40$ & 284,88 & 142,44 & 218,24 & 264,72 & -66.64 & $+122,28$ \\
\hline 9. & Ulee Kareng & 615,00 & 123,00 & 61,50 & 25,54 & 306,15 & -97.46 & $+244,65$ \\
\hline Total & & $6.136,00$ & $1.227,18$ & 613.59 & 810,53 & $1.490,90$ & $-416,68$ & $+781,64$ \\
\hline
\end{tabular}

Perbandingan kecukupan kebutuhan RTH publik berdasarkan luas wilayah dengan kondisi saat ini di Kota Banda Aceh memperlihatkan bahwa secara keseluruhan total RTH publik Kota Banda Aceh saat ini seluas 810,52 ha. atau 13,2\% dari $20 \%$ yang disyaratkan. Luas eksisting RTH Publik tersebut masih belum memenuhi luas minimum yaitu 1.227,18 
ha, masih kurang 416,68 ha atau 7,8\% sebagaimana yang ditetapkan oleh UU No. 26 Tahun 2007 Tentang Penataan Ruang.

\section{Kebutuhan RTH Berdasarkan Jumlah Penduduk}

Hasil Pertumbuhan penduduk kota Banda Aceh rata-rata 2,3 \% per tahun, dengan menggunakan persamaan model bunga berganda yaitu $\mathrm{Pt}=\mathrm{Po}(1+\mathrm{r})^{\mathrm{t}}$, diproyeksikan pada tahun 2029 (masa RTRW Kota Banda Aceh) jumlah penduduk Kota Banda Aceh 343.944 jiwa. Ditjen Penataan Ruang (2008) menetapkan standar luas minimum kebutuhan RTH perkotaan secara kuantitatif didasarkan pada jumlah penduduk adalah $20 \mathrm{~m}^{2}$ per kapita. Kebutuhan RTH Kota Banda Aceh akhir tahun perencanaan 2029 dapat dilihat pada Tabel 4.

Tabel 4. Kebutuhan RTH Kota Banda Aceh Berdasarkan Jumlah Penduduk Tahun 2029

\begin{tabular}{llrrrr}
\hline \multirow{2}{*}{ No. } & \multirow{2}{*}{ Kecamatan } & \multirow{2}{*}{ Jumlah Penduduk (Jiwa) } & \multicolumn{3}{c}{ RTH (ha) } \\
\cline { 3 - 6 } & & 26.163 & 52,33 & 187,61 & $+135,28$ \\
\hline 1. & Meuraxa & 33.750 & 67,50 & 23,15 & $-44,35$ \\
2. & Jaya Baru & 31.651 & 63,30 & 38,17 & $-25,13$ \\
3. & Banda Raya & 48.593 & 97,19 & 44,60 & $-52,59$ \\
4. & Baiturrahman & 33.886 & 67,77 & 23,25 & $-44,52$ \\
5. & Lueng Bata & 68.302 & 136,60 & 109,38 & $-27,22$ \\
6. & Kuta Alam & 17.688 & 35,38 & 140,59 & $+105,21$ \\
7. & Kuta Raja & 49.217 & 98,43 & 218,24 & $+119,81$ \\
8. & Syiah Kuala & 34.696 & 69,39 & 25,54 & $-43,85$ \\
9. & Ulee Kareng & 343.944 & 687,89 & 810,52 & $+122,63$ \\
\hline \multicolumn{2}{l}{ Total } & & & &
\end{tabular}

\section{Arahan Pengembangan RTH Kota Banda Aceh}

Berdasarkan UUPR No. 26 Tahun 2007 maka kondisi RTH Kota Banda Aceh saat ini secara umum telah memenuhi standar $30 \%$ dari luas wilayah. Hal ini dikarenakan luas RTH privat yang dimiliki Kota Banda Aceh lebih dari $10 \%$ yaitu 22,75 \% dari luas wilayah, namun RTH publik sendiri baru mencapai 13,20\% dari 20\% yang dipersyaratkan. Hasil perhitungan kebutuhan RTH Kota Banda Aceh berdasarkan luas wilayah lebih optimal dibanding berdasarkan jumlah penduduk. Selain Kec. Meuraxa dan Kuta Raja, Kota Banda Aceh masih kekurangan RTH publik seluas 416,68 ha di 7 kecamatan lainnya. Arahan pengembangan RTH Kota Banda Aceh untuk ketujuh kecamatan tersebut diuraikan pada Tabel 5.

Tabel 5. Arahan Pengembangan RTH Kota Banda Aceh Tahun 2029

\begin{tabular}{|c|c|c|c|}
\hline No. & Jenis RTH & Lokasi & Arahan \\
\hline 1. & $\begin{array}{l}\text { RTH } \\
\text { Pertamanan }\end{array}$ & $\begin{array}{l}\text { Seluruh kecamatan } \\
\text { di Kota Banda Aceh }\end{array}$ & $\begin{array}{l}\text { - Perlu penambahan jumlah tanaman sebagai tanaman } \\
\text { pelindung di kawasan Masjid Raya Baiturrahman yang } \\
\text { disesuaikan dengan bentuk dan tinggi masjid. } \\
\text { - Pengembangan Taman Putro Phang dilakukan dengan } \\
\text { perawatan dan penataan kembali tanpa menghilngkan } \\
\text { nilai sejarah yang terkandung didalamnya. } \\
\text { - Penataan ulang kawasan Simpang Surabaya } \\
\text { menggunakan vegetasi yang tidak memiliki ketinggian } \\
\text { sehingga tidak mengganggu pengendara. } \\
\text { - Lahan masjid, sekolah, dan lahan terbuka diantara } \\
\text { pemukiman, dapat dimanfaatkan sebagai taman } \\
\text { lingkungan yang mampu mewadahi aktivitas masyarakat } \\
\text { dan meningkatkan kualitas lingkungan pada area } \\
\text { pemukiman tersebut. }\end{array}$ \\
\hline
\end{tabular}




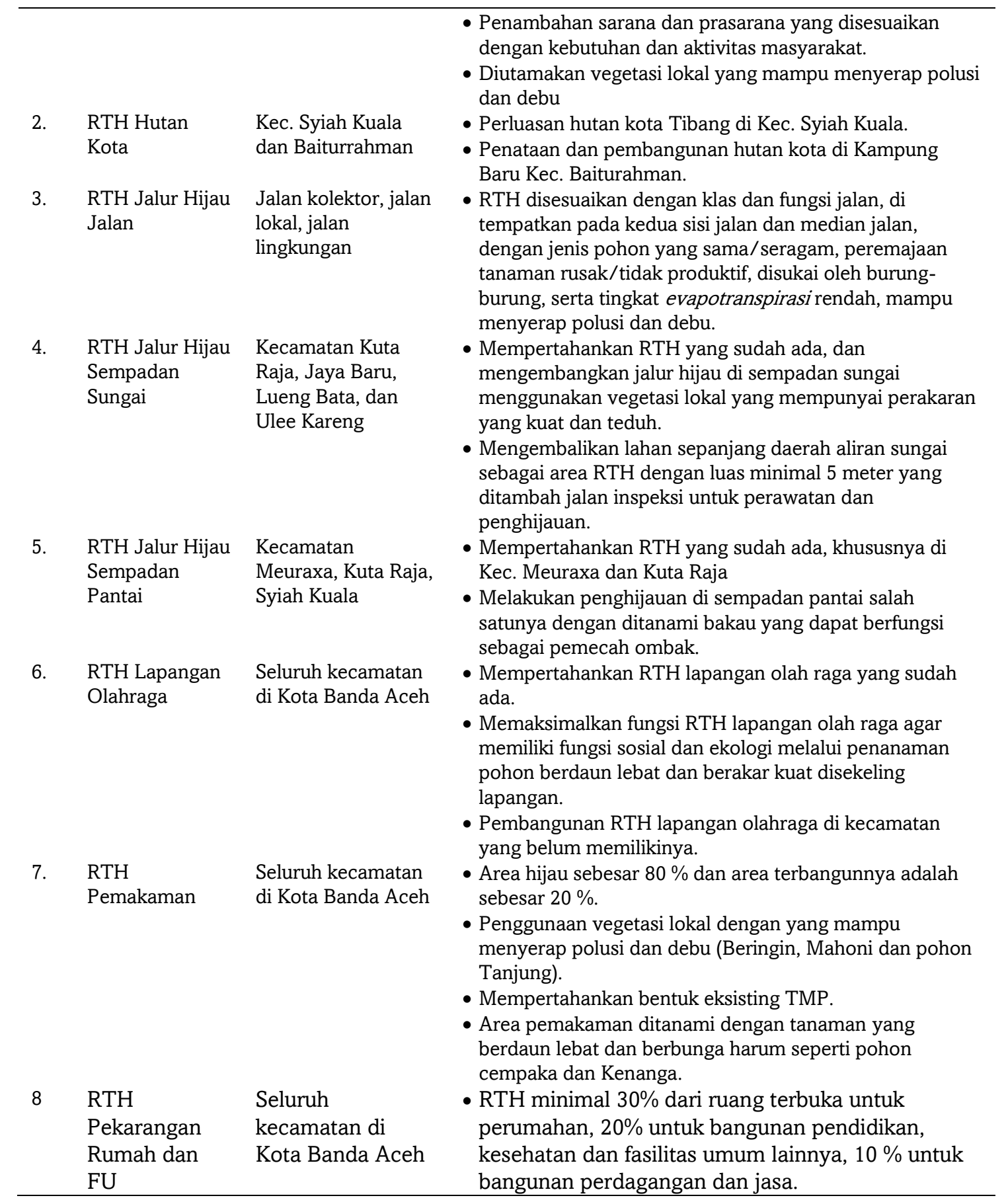

Pengembangan RTH dengan cara mengkonversi lahan warga, atau mengalokasikan RTH privat menjadi bagian dari RTH publik membutuhkan dana yang tidak sedikit, terutama dikarenakan harga tanah di Kota Banda Aceh yang terus mengalami kenaikan dan berbeda tergantung lokasi. Sebagai contoh harga tanah di pusat kota atau dekat dengan jalan berkisar antara Rp. 4.000.000-Rp. 5.000.000 per $\mathrm{m}^{2}$, sedangkan untuk lokasi yang berada di pinggiran kota dan pesisir harga tanah berkisar antara Rp. 500.000-Rp. 1.000 .000 per $\mathrm{m}^{2}$. Pemerintah Kota Banda Aceh sendiri menganggarkan dana sebesar Rp. 4 milyar setiap tahunnya untuk membangun RTH kota. Adapun perkiraan kebutuhan biaya pembebasan lahan untuk memenuhi sisa 416,68 ha kebutuhan RTH publik hingga 
tahun 2029 dengan asumsi harga lahan Rp. 800.000 per $\mathrm{m}^{2}$ dan kenaikan harga lahan $10 \%$ tiap 5 tahun sekali adalah sebagai berikut (Tabel 6):

Tabel 6. Perkiraan Biaya Pembebasan Lahan Untuk RTH Tahun 2029

\begin{tabular}{lcccc}
\hline & Tahun & $\begin{array}{c}\text { Kebutuhan } \\
\text { (ha) }\end{array}$ & $\begin{array}{c}\text { Harga lahan per m }{ }^{2} \\
(\mathrm{Rp})\end{array}$ & $\begin{array}{c}\text { Biaya } \\
(\text { Rp x 1.000) }\end{array}$ \\
\hline $\begin{array}{l}\text { Kebutuhan 5 tahun } \\
\text { pertama }\end{array}$ & $2016-$ & 148,00 & 800.000 & 1.184 .000 .000 .000 \\
Kebutuhan 5 tahun kedua & 2021 & & & 1.320 .000 .000 .000 \\
& $2021-$ & 150,00 & 880.000 & 1.245 .041 .600 .000 \\
$\begin{array}{l}\text { Kebutuhan 3 tahun } \\
\text { terakhir }\end{array}$ & 2026 & & & \\
\hline Total biaya (Rp) & $2026-$ & 128,62 & 968.000 & \\
\hline
\end{tabular}

Dengan hanya setiap tahun Pemerintah Kota Banda Aceh mampu menyediakan dana sebesar Rp. 4 milyar, maka lahan yang mampu disediakan untuk RTH hanya seluas 5.000 $\mathrm{m}^{2}$ atau 0,5 ha saja per tahunnya dengan asumsi harga lahan tidak mangalami kenaikan, dan hanya berlaku untuk lahan yang berada di pinggiran kota atau daerah pesisir. Hal penting yang perlu diingat adalah proses pembebasan lahan ini jangan sampai mengesampingkan hak dan kepentingan warga. Warga haruslah diberikan harga yang pantas untuk lahan yang mereka serahkan sesuai dengan harga yang berlaku di pasaran, pemberian insentif bagi warga yang mengizinkan lahannya diakuisisi misalnya berupa keringanan pajak, pajak air tanah, pembayaran tagihan listrik dan telepon. Berikut peta usulan pengembangan RTH Kota Banda Aceh hingga tahun 2019 (Gambar 2).

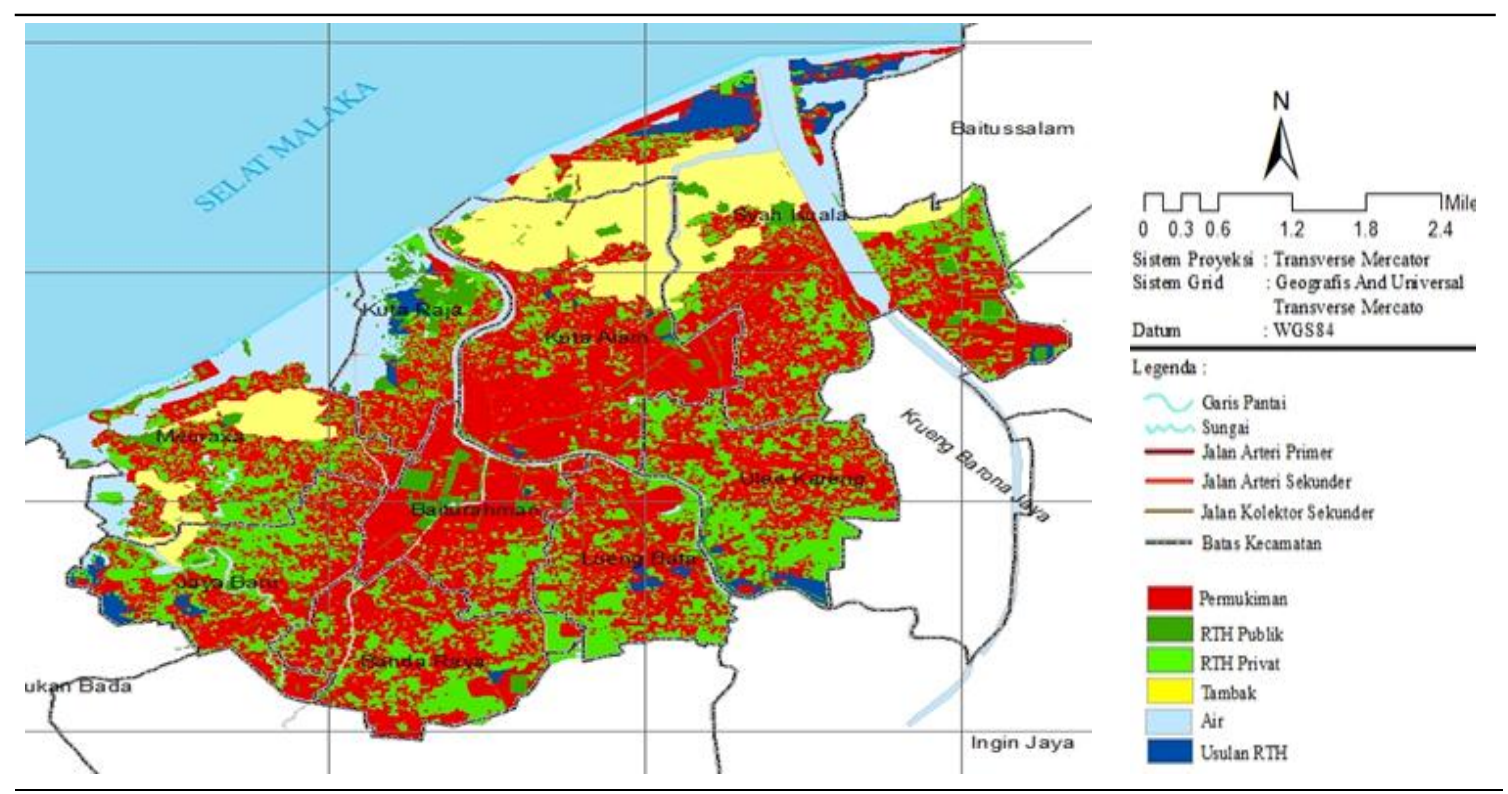

Gambar 2. Usulan Pengembangan RTH Kota Banda Aceh Tahun 2029

\section{KESIMPULAN}

Bencana tsunami tahun 2004 berdampak terhadap rusaknya RTH Kota Banda Aceh dari 853,87 ha menjadi 570,96 ha. RTH tahun 2010 yaitu seluas 787,09 ha, dan pada tahun 2015 luas RTH mengalami peningkatan yang sangat signifikan menjadi 2.301,47 ha. Berdasarkan standar luas RTH yang ditetapkan Undang-Undang Nomor 26 Tahun 2007 sebesar $30 \%$, ketersediaan RTH Kota Banda Aceh secara keseluruhan masih mencukupi hal ini dikarenakan luasnya RTH privat. Namun untuk RTH publik $20 \%$ masih belum terpenuhi 
atau kekurangan 416,68 ha dari luas wilayah kota. Arahan pengembangan RTH publik Kota Banda Aceh dititikberatkan pada pemenuhan kekurangan 416,7 ha dengan melakukan penghijauan diseluruh wilayah kota, menata dan memperbanyak taman kota, mendorong masyarakat untuk menanam pohon di pekarangan mereka, gerakan penghijauan bekerjasama dengan berbagai pihak, menempatkan tempat sampah dan papan tanda larangan membuang sampah di taman-taman kota dan kawasan wisata, mempertahankan fungsi dan menata RTH yang telah ada, menata dan mengembangkan RTH pada kawasan perdagangan dan permukiman sehingga dapat berfungsi lebih maksimal.

\section{DAFTAR PUSTAKA}

[BAPPEDA] Pemerintah Kota Banda Aceh. 2009. Tentang Rencana Tata Ruang Wilayah (RTRW) Kota Banda Aceh Tahun 2009-2029. Banda Aceh (ID): BAPPEDA Kota Banda Aceh

[BPN] Badan Pertanahan Nasional NAD. 2005. Peta Tingkat Kerusakan karena Gelombang Tsunami di Banda Aceh. Banda Aceh (ID): BPN

[BPS] Badan Pusat Statistik. 2016. Kota Banda Aceh Dalam Angka 2016. Banda Aceh (ID): Badan Pusat Statistik

BAPPENAS and The International Donor Community. 2005. Notes on Reconstruction - The December 26, 2004 Natural Disaster. Jakarta

Chiesura, A. (2004). The role of urban parks for the sustainable city. Landscape and Urban Planning, 68(1), 129138.

[Departemen PU] Departemen Pekerjaan Umum. 2008. Peraturan Menteri Pekerjaan Umum Nomor 05/PRT/M/2008 tentang Pedoman Penyediaan dan Pemanfaatan Ruang Terbuka Hijau di Kawasan Perkotaan. Jakarta (ID). Departemen Pekerjaan Umum

[Departemen PU] Ditjen Penataan Ruang. 2008. Pedoman Penyediaan dan Pemanfaatan Ruang Terbuka Hijau di Kawasan Perkotaan. Jakarta (ID). Departemen Pekerjaan Umum

[Kementerian PUPR] Kementerian Pekerjaan Umum dan Perumahan Rakyat. 2016. Panduan Penyelenggaraan Pengembangan Kota Hijau. Jakarta (ID): Direktorat Jenderal Cipta Karya, Kementerian Pekerjaan Umum

[Sekretariat Negara] Pemerintah Republik Indonesia. 2007. Undang-Undang Nomor 26 Tahun 2007 tentang Penataan Ruang. Jakarta (ID): Sekretariat Negara Republik Indonesia

Tanioka Y, Kusunose T, Kathiroli S, Nishimura Y, Iwasaki S, Satake K. 2006. Rupture process of the 2004 great Sumatra-Andaman earthquake estimated from tsunami waveforms. Earth Planets Space. 58, 203-209

Yuhong T, Jim CY, Haiqing W. 2014. Assessing the landscape and ecological quality of urban green spaces in a compact city. Landscape and Urban Planning 121: 97-108.

Zhou, X., \& Wang, Y.-C. (2011). Spatial--temporal dynamics of urban green space in response to rapid urbanization and greening policies. Landscape and Urban Planning, 100(3), 268-277.

Zaiyana D, Buchori I. 2014. Kajian Kembali Terhadap Risiko Tsunami Kota Banda Aceh. Jurnal Teknik PWK. 3. (4): hal. $807-817$ 